\title{
Histopatthological Changes in Liver of Albino Rat Induced by Experimental Infection of A. lumbricoides
}

\author{
Dr. Savita Rani
}

D.N. College, Meerut, India

\begin{abstract}
Ascarislumbricoidesis a gastrointestinal parasite infects the digestive tracts of humans, causing Ascariasis, and is estimated to infect approximately 1.4 billion persons on a global basis. During the following investigations various immunopathological changes were observed in low and high doses of infection. Changes were evident in hepatic cells, sinusoids, central and portal vein. These were cloudy swelling, fatty cyst formation, kupffer cell hyperplasia and inflammation. In the present studies kupffer cell hyperplasia, focal collections of lymphocytes were observed in high dose of sixty days of post-infection.
\end{abstract}

Keywords: Ascaris lumbricoides, Albinorat, Hyperplasia, Inflammation

\section{Introduction}

Ascaris lumbricoides infection represent a major public health problem in poor and developing countries and have constitute universal burden which does not only depend on regional ecological condition but also on local standard of social and economic, development of the people ( Ukbai et al, 2003). Ascariasis an intestinal worm infection is caused by the parasite Ascaris lumbricoides and a report by World Health Organization (WHO) on soil transmitted helminthes suggests that over one billion people are affected by Ascariasis. This disease is preventing in developing countries and in places of poor sanitation and unhygienic conditions. Even through anthelminthic drugs are available for the treatment of Ascariasis, it is considered as a neglected tropical disease.

\section{Material and Method}

The experiments were conducted on infection free laboratory maintained albino rats. The adult parasites were obtained from the intestine of freshly slaughtered sheep and kept in normal saline for egg laying. Sodium bicarbonate culture fluid was used for culturingA. lumbricoides eggsup to embryonated stage. The experimental protocol comprises of control group (6rats), second treated group were administered a low dose of (500 embryonated eggs) of $A$. lumbricoides (6 rats) and third group were administered a high dose of (1000 embryonated egg) of A. lumbricoides eggs (6 rats). 2 rats from each group were sacrificed after 20 , 40, 60 days of post infection. The tissues (liver) were further processed for microtomy and microphotographs.

\section{Observation}

Following changes were observed due to infection of $A$. Lumbricoidesin liver.

Changes in the liver of albino rats due to infection with low dose (500 embryonated eggs ) of A. lumbricoides

After 20 days of post-infection
Hepatocytes showed minimal degree of cloudy swelling. Sinusoids appeared normal and no kupffer cell hyperplasia was seen. No specific alteration in portal tract.

\section{After 40 days of post infection}

Hepatocytes revealed degenerative changes, fatty cysts formation. Portal tract revealed fibrosis; inflammatory cells mainly lymphocytes and macrophages.

\section{After 60 days of post infection}

Hepatocytes characterized by feathery appearance of cytoplasm. Nuclear changes like cyanosis, karyolitic were observed. Sinusoids with kupffer cell hyperplasia observed. Prominent fibrosis characterized by oblong nuclei seen around portal tract

\section{After 60 days of post-infection \\ Hepatocytes characterized by feathery appearance of cytoplasm. Nuclear changes like pyknosis, karyolysis and karyorrehexis were observed (fig 3). Sinusoids with kupffer cell hyperplasia observed. Prominent fibrosis characterized by oblong nuclei seen around portal tract (fig 4). I}

Changes in the Liver of Albino Rats Due to Infection with High Dose (1000 EMBRYONATED EGGS) OF T.OVIS

\section{After 20 days of post-infection}

Mild degree of perilobular fibrosis was recorded in hcpatocytes. Dilation of central Vein and sinusoids (fig 5).

\section{After 40 days of post-infection}

Few lymphocytes were scattered diffusely in the liver lobule. Thick fibrous band withprominent vessels and bile ductile were evident in portal area (fig 6).

After 60 days of post-infection.

Central vein and sinusoids appeared to be degenerative, necrotic changes were discerned. Kupffer cells seen in fair number. Focal collection of lymphocytes in portal tract (fig 7). 


\section{International Journal of Science and Research (IJSR) \\ ISSN (Online): 2319-7064}

Index Copernicus Value (2013): 6.14 | Impact Factor (2014): 5.611

\section{Discussion}

During the following investigations various immunopathological changes were observed in low and high doses of infection. Changes were evident in hepatic cells, sinusoids, central and portal vein. These were cloudy swelling, fatty cyst formation, kupffer cell hyperplasia and inflammation. Changes in hepatocytes have beenreported by Mossoud (1981) in the sheep naturally infected with Dicrocoeliumdendriticum. Fatty cyst formation in liver may be due to the interference in the fat metablosim of the liver. Dilation of central vein may be due to the normal tissue response towards internal parasite. Due to low and high dose of infection the liver of albino rats revealed cloudy swelling which is due to the toxins and antigen liberated by the parasite, an important pathological alteration in hepatocytes. In the present studies kupffer cell hyperplasia, focal collections of lymphocytes were observed in high dose of sixty days of post-infection. Pathomorphological changes were similarly observed in the liver of lambs after long term Ascaris suum infection (Krupiceret al 1999). Portal area revealed fibrosis, dilation and congestion sinusoids, degenerative changes in the nucleus. These changes were due to deficient blood supply, inadequate nutrition and oxygenation. Fibrosis in portal tract was observed by Radhaet al (2003). Changes in the liver parenchyma was also studied by Perez et al (1999). Present author is of the opinion that various immunopathological alterations may be due to endotoxins liberated by the parasites. The stimulation of liver collagen synthesis and promotion of collagenolysis in schistosomiasis are thought to be indirect result of immunological host responses to schistosome egg antigen. A linkage between the parasite infection and these processes that take place between the parasite and the host's collagen metabolic pathways are responsible for above pathological changes. Anderson (2001) studied on ascaris that the dangers of using single locus markers in parasite epidemiology:. Crompton (2001) and Bethony et al., (2006) worked on Ascaris and ascariasis. And studiede on soiltransmitted helminth infections: ascariasis, trichuriasis and hookworm. Parvatham and Veerakumari, (2013) observed on Drug target prediction using elementary mode analysis in Ascaris lumbricoides energy Metabolism. Biotechnology and bioprocess engineering

\section{Acknowledgement}

Authors are thankful to the Head Department of Zoology, D.N. College, Meerut for providing all the laboratory facilities.

\section{References}

[1] Crompton, D.W.T. (2001): Ascaris and ascariasis. Advances in Parasitology, vol, 48, pp-285-375.

[2] Jelliffe, D.B (1953): Ascaria lumbricoides and malnutrition, in tropical

[3] Children.Document?Jcimdicinegcographicu el tropical.5:314-320.

[4] Bethony, J., Brooker, S., Albonico, M., Geiger, S.T., Loukas, A., Diemert, D., and Hotez, P.J. (2006): soiltransmitted helminth infections: ascariasis, trichuriasis and hookworm. Vol, 367, pp-6-12.

[5] Krupicer, I; Ondrejka, R; Svicky, E; Vasilkova, Z; Dovroznakova, E; Dubinsky, P; Moncol, D.J. (1999): Clinical and pathomorphological changes in the organism of lambs after long term Ascaris suum infection. Klinicke a patomorjbrogicke $\mathrm{z}$ meny $\mathrm{v}$ organizrnejahnial pod thodobominfikovani.vajickamiAscaris suum SolvenskyVeterinarskyCasopis(1999) 24 (2) 93-97

[6] Massoud, J (1981): Histopathology of liver in Iranian sheep naturally infected with Dicrocoeliumdendriticium. Annals of Tropical Medicine and Parasitol.75(3): 293-298.

[7] Perez, J; Martin de lasMulas, J; Carrasco, L; Gutierrez, P.N; Martinez-Cruz, M.S; Martincz-Moreno, A (1999): Pathological and Immunohistochemical study of the liver and hepatic lymph nodes in goats infected with one or more doses of Fasciola hepatica. J. Comp. Patho. Vol.120, 199-120. :

[8] Radha, G; llurikrishan, T.J; Anna, T (2003): Pathology of experimental coccidiosis in lambs. Indian.Journal of Animal Sciences.73(5): 532-533

[9] Smith, J.D (1908): Cited from "Animal Parasitology". Cambridge University Press.

[10] Parvatham,k, and Veerakumari, L.(2013): Drug target prediction using elementary mode analysis in Ascaris lumbricoides energy Metabolism. Biotechnology and bioprocess engineering 18: 491-500.

[11] Anderson, Tim,J.C.(2001): the dangers of using single locus markers in parasite epidemiology: Ascaris as a case study. Vol, 17, pp-183-188.

[12] Tripathy, K; Kuque, E; Bolanos, O; Lotero, $\mathrm{H}$ and Mayoral, L.G (1972): Clinical nutrition, 25; 1276-1281.

[13] World Health Organization (1967): Control of ascariasis, WHO. Technical Report no 314. 
International Journal of Science and Research (IJSR)

ISSN (Online): 2319-7064

Index Copernicus Value (2013): 6.14 | Impact Factor (2014): 5.611
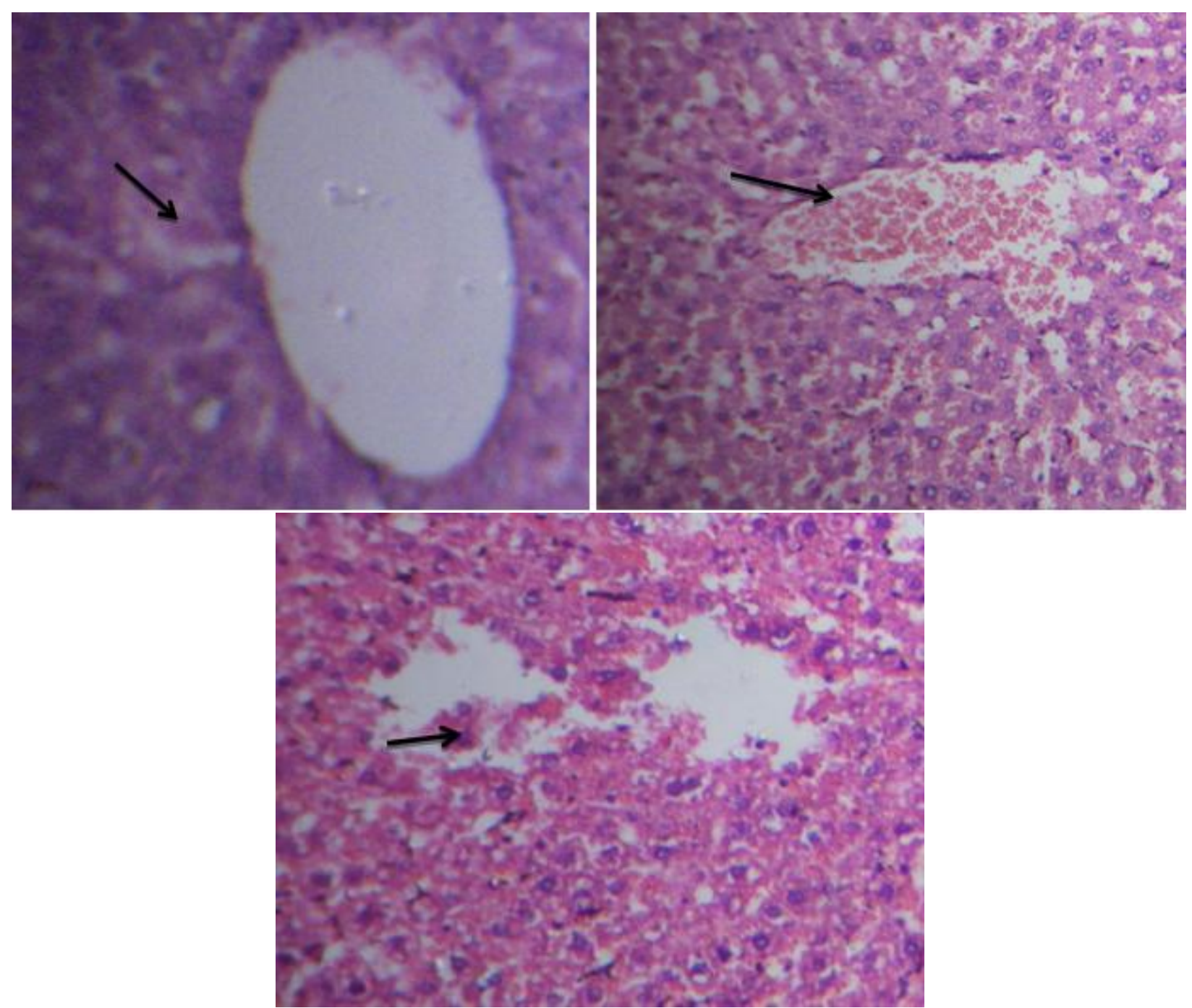

Figure 1 show dilation \& central vein, fig2, show, Necrosis.Mid cloudy swelling. Focal collection of Lymphocytes, hemorrhage in central vein. Fig 3, show inflammatory changes in hepatic cell sinusoids, Kupffer cell hyperplasia 